\title{
ESTRATEGIAS IDENTITARIAS DE LOS INMIGRANTES ARGENTINOS Y ECUATORIANOS EN MADRID
}

\author{
PAOLA GARCÍA \\ TRAVERSES, Université Paris 8 - Instituto Ortega y Gasset.
}

\section{RESUMEN}

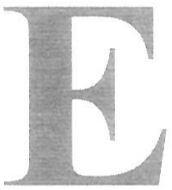

ste trabajo pretende analizar las estrategias identitarias que los inmigrantes argentinos y ecuatorianos desarrollan en un mismo espacio geográfico. La problemática general consiste en preguntarse en qué medida el contenido simbólico de las identidades atribuidas por la sociedad receptora, como así también el grado de estigmatización que caracteriza a los argentinos y ecuatorianos, influyen en los comportamientos identitarios de cada grupo. La investigación se desarrolló a partir de un trabajo de campo realizado en Madrid y en Buenos Aires en el año 2003 y en el año 2004. En Madrid fueron entrevistados residentes jóvenes argentinos y ecuatorianos de 20 a 35 años, y en Buenos Aires padres de jóvenes inmigrantes residentes en España y argentinos de regreso o a punto de partir.

Palabras clave: identidad, migración, Argentina, España, Ecuador.

\section{INTRODUCCIÓN}

El estatuto de inmigrante que caracteriza al individuo en el país receptor, su nuevo estatuto profesional y social, las identidades estigmatizantes que le son atribuidas, las diferencias culturales y lingüísticas inesperadas en el caso de los latinoamericanos, y sobre todo, la confrontación de los proyectos iniciales con las posibilidades reales de realización en el país receptor, provocan un fuerte cuestionamiento de sí mismo y exigen una "remodelación" costosa de la identidad. Esta remodelación se efectúa, en el caso de los inmigrantes instalados en España, a partir de una relación a menudo asimétrica entre el grupo mayoritario, constituido por los españoles, y el grupo minoritario de los inmigrantes extracomunitarios.

El inmigrante surge como actor social importante en España en los años 80, cuando el país se democratiza y entra a formar parte de la Unión Europea. En 1985, el gobierno español crea el primer marco legal y jurídico con la Ley Orgánica para caracterizar a la inmigración y la figura social del inmigrante se define entonces a partir de su pertenecia o no a la Unión Europea y de su estatuto de inmigrante legal o ilegal. Paralelamente al cuadro jurídico, la apa- 
rición de este nuevo actor social provoca la emergencia en el imaginario de la sociedad española de un conjunto de representaciones sociales que permiten identificarle, atribuyéndole características identitarias arbitrarias. Surge entonces lo que Santamaría (2002) denomina "el inmigrante imaginado".

La categorización del inmigrante extracomunitario, que en realidad resulta ser un intento de definición de la alteridad, se construye a partir de la percepción desvalorizada que la sociedad de recepción tiene de los países de origen de la inmigración extracomunautaria. Estos son a menudo percibidos como "subdesarrollados", "miserables" y "atrasados". A estas imágenes negativas se oponen la modernidad y el progreso que España reivindica hoy en día. Así, la dicotomía inegalitaria "Norte-Sur", "país desarrollado-país tercermundista" genera, por parte de la sociedad española, una mirada miserabilista y paternalista sobre los inmigrantes extracomunitarios.

A esta mirada compasiva, se suma una mirada más hostil que (re) presenta a la immigración extracomunitaria como amenaza. Esta representación surge en gran parte de la gran abundancia en la prensa nacional de metáforas guerreras' y cataclísmicas ${ }^{2}$ que caracterizan a la inmigración extracomunitaria. Además, se percibe a menudo esta inmigración como "problema" por relacionarla con la delincuencia, la inseguridad, el desempleo, etc. (Santamaría, 2002).

Al llegar a España, el inmigrante se enfrenta, pues, a este conjunto de imágenes fuertemente negativas a través de las cuales la sociedad española va a definirlo y atribuirle una identidad. Pero, ¿todos los grupos de inmigrantes son percibidos de la misma manera?, ¿cómo se representan los españoles a los latinoamericanos?, ¿existen diferencias en la percepción de cada grupo latinoamericano? Frente a las identidades atribuidas, ¿cómo reaccionan los inmigrantes?, ¿cómo los argentinos y ecuatorianos reconstruyen su identidad?

Para contestar a estos interrogantes, nuestro análisis, basado en un trabajo de campo, se organiza en dos partes. En la primera parte, analizamos la figura simbólica que la sociedad española construye sobre los inmigrantes argentinos y ecuatorianos. En la segunda parte, destacamos las estrategias que los inmigrantes argentinos y ecuatorianos desarrollan para enfrentar la desvalorización de sus identidades.

\section{ETIQUETAS ESTIGMATIZADAS}

En sus primeros intentos de integración a la sociedad de acogida, el inmigrante descubre una identidad simbólica positiva o negativa que tanto la sociedad de origen como los demás grupos de inmigrantes han irremediablemente atribuido a su grupo (Camilleri, 1990). Numerosos estudios realizados sucesivamente entre 1995 y 1997 en la sociedad española (Blanco, 2000: 173), muestran cómo los españoles valoran a las diferentes poblaciones de inmigrantes presentes en su territorio. De las 1.204 personas consultadas, $42 \%$ afirman su preferencia por los latinoamericanos dentro del grupo de inmigrantes

1 "Invasión", "ilegal", "clandestino", "tráfico de inmigrantes", "bombas demográficas", etc.

2 "Flujos", "olas migratorias", "avalanchas", "mareas crecidas", etc. 
extracomunitario. Estudios más recientes (Calvo Buezas, 2000) confirman esta tendencia. Así como la opinión pública española parece más dispuesta a aceptar a los inmigrantes latinoamericanos, el sector empresarial también les favorece conviertiéndoles en los preferidos del siglo XXI (Izquierdo \& all, 2002). Sin embargo, no todos los inmigrantes latinoamericanos son percibidos de la misma manera. ¿Cuál es la representación social que la sociedad española elabora más específicamente sobre los colectivos de inmigrantes argentinos y ecuatorianos? ¿Qué identidades simbólicas les atribuye? En la siguiente parte analizamos la representación social construida alrededor de la figura de los ecuatorianos y argentinos a partir de los discursos cruzados (simbólicos e ideológicos) de los inmigrantes entrevistados y de los españoles, representados en particular en la prensa nacional española.

\subsection{Los argentinos 3}

La principal diferenciación que se establece entre inmigrantes latinoamericanos está ligada a características físicas. Los argentinos y uruguayos, provenientes de la inmigración europea reciente, son físicamente más parecidos a los españoles. Estas características conllevan generalmente de parte de la sociedad española preferencias por el grupo sudamericano que parece perfectamente "asimilable". El inmigrante lo resiente inmediatamente y es frecuente escuchar en su boca argumentaciones como la siguiente:

"El argentino pega bien porque es ingenioso, trabajador y emprendedor. Y también porque tiene rasgos europeos. He descubierto que los españoles son un poco racistas y los rasgos fisicos indigenas no les gustan demasiado".4

Los inmigrantes argentinos gozan de una invisibilidad física en relación a otros colectivos y, en consecuencia, no sufren de una asignación étnica específica. A su vez, esta invisibilidad física se acompaña de una visibilidad mediática, cultural y lingüística mayor a la de otros colectivos latinoamericanos. En un estudio sobre la representación de los latinoamericanos en la prensa española, Jessica Retis (2004:13) constata que: "A diferencia de otros colectivos, el discurso público reflejado en la prensa si fue constatando tanto la crisis económica como la salida de los argentinos en su país. (...) Esta [la crisis] se ha visto no sólo como un problema de este país, sino también como un suceso que preocupa a España (...). "A tal punto que, en los momentos más críticos de la crisis, algunos periódicos relegaron las noticias en primera página (op.cit).

La visibilidad de la crisis argentina y la emoción que sintió la sociedad española frente a este suceso se explican en parte por los lazos históricos, migratorios y comerciales que unen a los dos países. La sociedad española parece entender y compadecerse con la desesperación de los miles de profesionales de clase media víctimas de la crisis que deciden emigrar a España. Estos emigrantes que huyen de su país son percibidos y acogidos como víctimas de un régimen corrupto y mafioso, responsable del desastre económico, social y

3 En 2003, 109.000 argentinos se empadronaron en España. En el municipio de Madrid, fueron 10.983 argentinos (Boletín Madrid Datos, Consejería de Gobierno de Hacienda y Administración pública: "Población extranjera en el Municipio de Madrid. Padrón municipal de habitantes al 1 de enero del 2004").

4 La Nación, (01/07/01), Pisani, S., "Buscando adaptarse a una vida «muy dura»". 
político del país. Contrariamente a las demás emigraciones, la argentina aparece más bien como coyuntural. Argentina, percibida en el imaginario español como un país rico y triunfante, aparece de repente como frágil y parte del tercer mundo.

Esta visibilidad mediática se acompaña de una cierta visibilidad lingüística y cultural. Por una parte, los particularismos idiomáticos y la manera de hablar de los argentinos están de moda, a tal punto que se han vuelto argumentos marketings ${ }^{5}$. Por otra parte, actualmente muchos argentinos trabajan en el sector audiovisual español y contribuyen a la visibilidad de su grupo en este sector. Además, desde hace años, el cine y el teatro argentino participan de la vida cultural española y aún más desde la crisis de 2001. En aquel momento, los artistas argentinos desarrollan un tipo de "resistencia cultural", produciendo obras esencialmente cinematográficas y teatrales que reciben una muy buena acogida en España e influyen favorablemente en la percepción de los españoles como lo testifican las palabras de un joven argentino: "La movida cultural argentina está llegando a España y te refleja de cierta forma, te muestran y te humanizan ...."?

Los españoles están, por lo tanto, en contacto con expresiones lingüísticas y culturales argentinas e informados de lo que ocurre en el país. Este conocimiento del "otro" permite que la figura simbólica del inmigrante argentino se construya a partir de una alteridad identificable $y$, por consiguiente, poco amenazante. El argentino percibe entonces una apertura por parte de los españoles que favorece indiscutiblemente la interacción social entre los dos grupos:

"Los argentinos están de moda en España. Cuando decís que sos argentino, te dicen: "iHay qué lindo!". Están muy preocupados por aprender tus costumbres, saber lo que está pasando en tu país. Los españoles están muy informados con la crisis argentina. Eso no le pasa al colombiano, al mexicano. Eso le pasa sólo al argentino (...) Son modas. No te reprochan realmente la forma de hablar, al contrario, le copian un montón de cosas como hablar de "vos". Todo el mundo se sorprende de que no se me hayan pegado palabras españolas. Pero a mi me parece que todas mis amigas españolas están más argentinizadas que yo. Se les pegan palabras como "boludo", "plata”. Hablando entre ellas se les pega". ${ }^{8}$

Sin embargo, la actitud de los españoles descrita en este testimonio es quizás más característica de la juventud española. El contexto en el que esta joven argentina se desenvuelve no es el profesional sino el universitario. En el ámbito profesional se instauran relaciones de fuerza que pueden generar conflictos y discriminación. El inmigrante argentino tiene un perfil profesional que le

5 En una publicidad de la bebida gaseosa Fanta aparece la palabra: "Quilombo".

6 Cf. La Nación On line, 31/12/02, Reinoso, S., "La cultura consiguió sobrevivir a la crisis".

7 Fabio, 34 años, oriundo de la provincia de Buenos Aires. Cuando lo entrevistamos en marzo de 2003, llevaba dos años viviendo en Madrid. En Buenos Aires estudiaba Marketing y en España tenía un puesto en una empresa.

8 Cuando entrevistamos a Silvana en 2003, tenía 25 años y estaba residiendo en Madrid desde hacia cinco meses y medio. En Argentina estudiaba Diseño y había conseguido una beca en la Universidad de la Complutense para completar su formación. 
permite insertarse en el mismo sector laboral que el español y ambos están en competencia. En esas circunstancias, puede ocurrir que la forma de hablar del argentino se convierta también en un elemento discriminador por ser la principal marca identitaria visible del grupo. Por lo tanto, aunque los inmigrantes argentinos reciban una acogida favorable por parte de los españoles y provoquen curiosidad, siguen siendo considerados como extranjeros y pueden, en algunos casos, ser discriminados, como lo testifican las palabras de Silvia"

"El argentino no parece ser un latinoamericano, entonces nunca te van a pedir documentos o hacer un comentario. Sin embargo, no quiere decir que no haya rechazo. A veces hay gente que te discrimina porque te oye hablar diferente. El encargado de contrataciones me discriminaba. Siempre me sentaba atrás y cuando era otra persona la ponía adelante del todo. Era algo demasiado evidente. O también ocurre que te discriminen cuando buscas un alojamiento. Cuando llamas a una agencia para alquilar un departamento, entonces, te escuchan por alli el tono de voz y te cortan o te dicen que está alquilado. A nosotras nos pasó con una amiga y fue su tío-abuelo español quien terminó llamando a la inmobiliaria y le dijeron que sí y en menos de dos dias nos mostraron cinco pisos. Antes nos decían que los tenian en alquiler y en cuanto llamó un español fue diferente".

Además, el colectivo argentino inspira una cierta desconfianza tanto en los españoles como en los demás grupos latinoamericanos. Los latinoamericanos, en general, tienen una imagen negativa del argentino. Por lo general, el argentino es percibido como una persona "creída", que "se lleva el mundo por delante" y que no se siente latinoamericano, sino que reivindica sus orígenes europeos.

Esa impresión es frecuente entre los latinoamericanos:

"A primera vista, si tú vienes y me presentas a un chico argentino, el argentino es la típica persona pija, es una persona que no siente la raiz sudamericana porque se considera europeo, descendiente de gallegos, de italianos". 10

Por su parte, los argentinos están conscientes de producir ese efecto.

"En España, nosotros, los argentinos, tenemos que pelearla. Aqui, cuando decis que sos argentino, te miran mucho porque venimos con mucha soberbia, creyéndonos que éstos son unos gallegos cuadrados de mierda, piensan que queremos comernos el mundo. Sin embargo, es verdad que los argentinos somos el colectivo más aceptado porque tenemos el mismo nivel cultural que aqui, tenemos competencias fuertes"."

9 Silvia, de 37 años, flevaba viviendo en Madrid un año cuando la entrevistamos en 2003. En Argentina, era ingeniera de sistemas. En Madrid trabajaba de figurante.

10 Oscar, tenía 31 años cuando lo entrevistamos en 2004. Es oriundo de la región de Loja, Ecuador. Llevaba tres años viviendo en España. En Ecuador, trabajaba como agente vendedor de una empresa y en España trabajaba como mensajero.

11 Leo, 33 años, es originario de Buenos Aires capital y fue entrevistado en 2003. En Argentina, trabajaba como actor en el sector publicitario. En España sigue ejerciendo su profesión. 
Como señala el último testimonio, los argentinos gozan de condiciones de integración favorables, por lo cual algunos se definen como "inmigrantes de primera clase". Al hecho de que los españoles se interesen por la política y la cultura argentina, se suma la imagen precedente, por lo general positiva, de los exilados políticos. Estos exilados políticos, que llegaron a España a mediados de los 70, lograron una buena integración social y son, para la sociedad española, el marco de referencia a través del cual se construye la representación de los nuevos llegados.

La importancia de la figura del exilado político es real y se materializa, por ejemplo, en el interés mediático que despiertan hoy los eventos históricos y sociales ligados a la dictadura argentina (Retis, 2004).

Sin embargo, las representaciones sociales, lejos de ser fijas, evolucionan y la figura del inmigrante argentino corre el riesgo de ser asimilada a la de inmigrantes más estigmatizados. Por una parte, es cada vez más frecuente ver a argentinos vivir en condiciones precarias, sin empleo o trabajando en el servicio doméstico, sector de trabajo esencialmente destacado por la fuerte presencia de ecuatorianos, colombianos, peruanos, etc., compartiendo pisos con otros inmigrantes latinoamericanos, etc.

Por otra parte, la evolución de la representación es también el resultado de las reivindicaciones de los derechos de los inmigrantes argentinos de las asociaciones argentinas que, aunque tengan poco eco dentro del colectivo argentino, tienen una gran visibilidad mediática. Las asociaciones argentinas, como las demás asociaciones de inmigrantes, apuntan la situación de ilegalidad en la que viven muchos compatriotas y denuncian la falta de aplicación de los convenios bilaterales que garantizan un trato preferencial de los argentinos.

\subsection{Los ecuatorianos ${ }^{12}$}

El análisis comparado del colectivo argentino y del ecuatoriano deja vislumbrar diferencias importantes en la construcción simbólica que la sociedad de recepción elabora sobre cada colectivo. Si comparamos la aceptación de los ecuatorianos a la de los argentinos, puede afirmarse que la de los ecuatorianos es más problemática. En consecuencia, la interacción social entre españoles y ecuatorianos resulta más restringida, limitándose a menudo exclusivamente al ámbito laboral.

Los ecuatorianos tienen una visibilidad física mayor que la de los argentinos. Por una parte porque sus rasgos físicos revelan inmediatamente su origen indígena o mestizo. Por otra parte, porque tienen una visibilidad en tanto que comunidad numéricamente importante. Contrariamente a los argentinos, los ecuatorianos tienden a reagruparse en espacios circunscriptos, como parques o barrios ${ }^{13}$.

12 En 2003, los ecuatorianos pasaron a ser el primer colectivo extranjero en España con 390.000 ecuatorianos empadronados. En el municipio de Madrid se empadronaron 143.653 ecuatorianos (Boletín Madrid Datos, Consejería de Gobierno de Hacienda y Administración pública: "Población extranjera en el Municipio de Madrid. Padrón municipal de habitantes al 1 de enero del 2004").

13 Cf. El Pais, (26/09/04), ALIAS, M.D., NEUDECKER, M., "La pequeña, Quito empieza en Ventas" y MORENO LORITE \& all (2000). 
Tanto el colectivo argentino como el ecuatoriano están presentes en la prensa española. Sin embargo, en general, el contenido informativo es diferente. En primer lugar, la crisis ecuatoriana no aparece casi nunca mencionada y el lector español, al no tener informaciones sobre el contexto social y político que generó la salida de miles de ecuatorianos hacia España, no llega a comprender realmente las causas de esta emigración. El fenómeno migratorio ecuatoriano es entonces interpretado más bien como estructural. Es decir, que no parece estar ligado a una situación coyuntural desfavorable, sino que se interpreta como un fenómeno social característico de un país "pobre" y "subdesarrollado", imagen que parte de la opinión pública española tiene de Ecuador.

La representación simbólica del inmigrante ecuatoriano en el discurso de la prensa nacional se construye a partir de la exclusión y la marginalidad (Retis, 2003). La aparición de la figura del inmigrante ecuatoriano en España está ligada en general a la ilegalidad, al hacinamiento, a la explotación laboral, a los homicidas, a la delincuencia, a los disturbios provocados por el alcoholismo ${ }^{14}$ de ciertos ecuatorianos y por los encuentros organizados en espacios públicos como parques, canchas de fútbol, etc. La opinión pública española critica fuertemente estos encuentros porque, además del alboroto de la música, dejan los espacios sucios y deteriorados. Al inmigrante, se le acepta mientras no se le vea, mientras se mantenga recluido en el campo. Desde el momento en que ocupa espacios públicos, se hace visible y entra en conflicto con la población local.

A esta imagen estigmatizada del inmigrante ecuatoriano, se suma su invisibilidad lingüística y cultural. A pesar de su importancia numérica, el colectivo ecuatoriano está completamente excluido del espacio cultural nacional. La sociedad receptora convierte a este colectivo en inexistente y culturalmente deficiente.

La falta de información sobre la cultura del inmigrante ecuatoriano y sobre su país de origen genera en la opinión pública española cierto recelo y temor.

Los ecuatorianos también tienen que enfrentarse con la mirada de los demás colectivos de inmigrantes. Esta mirada varía en función de la nacionalidad del grupo porque, contrariamente a los argentinos, los ecuatorianos generan percepciones heterogéneas. Esto se debe, sin duda, a que los ecuatorianos, contrariamente a los argentinos, se relacionan casi exclusivamente con otros colectivos de inmigrantes y son caracterizados más bien a través de las relaciones interpersonales.

Los inmigrantes peruanos y los magrebíes son quienes vehiculan la imagen más negativa de los ecuatorianos. En parte, porque existen relaciones conflictivas entre Perú y Ecuador las que, muchas veces, cobran mayor importancia en España. En parte, porque los hombres ecuatorianos se insertan en los mismos sectores de trabajo ${ }^{15}$ que los peruanos y magrebíes y compiten con ellos. Es frecuente que se les reproche a los ecuatorianos dañar el mercado de trabajo

14 El ecuatoriano tiene fama de borracho, "se embriaga hasta perder la razón", según una opinión muy frecuente entre los españoles.

15 La construcción y la agricultura son los principales sectores laborales en los que se insertan estos inmigrantes (Anuario estadístico de Extranjería 2002, Delegación del Gobierno Para la Extranjeria y la Innigración, Ministerio del Interior, Madrid). 
aceptando salarios cada vez más bajos. Esto refuerza la percepción del inmigrante ecuatoriano como persona dócil que se deja voluntariamente explotar, como sugiere el testimonio de Abdul, inmigrante marroquí:

"Los españoles prefieren a los ecuatorianos porque nunca reclaman sus derechos, bajan la cabeza y por eso les pagan lo que les da la gana, pero los otros inmigrantes no les quieren porque desconfian de ellos, porque a veces son más malditos que los mismos españoles". ${ }^{16}$

En esta parte, intentamos mostrar que las condiciones de integración a la sociedad española de los ecuatorianos son más desfavorables que las de los argentinos. Los ecuatorianos reciben por parte de la sociedad de recepción una acogida más reservada y deben renegociar sus identidades a partir de etiquetas fuertemente estigmatizadas que desvalorizan al individuo. En cambio, los argentinos, menos estigmatizados $\mathrm{y}$, con mejor contacto con la población local, están definidos más bien a partir del aspecto personalizante. Los rasgos identitarios que les son atribuidos por la sociedad receptora son matizados y menos categóricos, lo cual les proporciona un margen de maniobra mayor en la elección de su posicionamiento cultural.

Los ecuatorianos, definidos a partir de sus características físicas y su pertenencia cultural de corte tradicional, se refuerzan considerándose solidarios de su grupo étnico y pueden llegar incluso a sentirse su representante. Esta tendencia a convertir el dilema identitario en una problemática comunitaria, limita la posibilidad -e incluso la libertad-de adaptación o cambios culturales del individuo (Camilleri, 1990).

\section{LAS ESTRATEGIAS IDENTITARIAS DE LOS INMIGRANTES ARGENTINOS Y ECUATORIANOS INSTALADOS EN MADRID}

El individuo realiza operaciones cognitivas o estrategias identitarias ${ }^{17}$ que le permiten actuar sobre las construcciones simbólicas de sus identidades para modificarlas, mantenerlas o matizarlas. Camel Camilleri (1990), investigador francés, fue uno de los que más contribuyó a desarrollar la noción de estrategia identitaria, a partir del campo de investigación de la psicología social. A raíz de sus investigaciones sobre los inmigrantes magrebíes instalados en Francia propone una tipología ${ }^{18}$ que utilizamos como marco de análisis de las trayectorias individuales de los inmigrantes argentinos y ecuatorianos entrevistados. Sin embargo, esta tipología de las estrategias identitarias no debe ser considerada definitiva ni cerrada. Un individuo puede perfectamente adoptar diferentes estrategias en función de la coyuntura. En la parte siguiente, analizamos las

16 Testimonio sacado de "España es una madrastra" de José Villarroel Yanchapaxi, (2003), Brecha, http://www. rel-uita.org/old/internacional/ecuador l.htm.

17 Las estrategias identitarias pueden ser consideradas como: "Procesos puestos en marcha (de forma consciente o inconsciente) por un actor (individual o colectivo) para llegar a una, o varias, finalidades (definidas explícitamente o situadas a nivel del inconsciente), procesos elaborados en función de la situación de interacción (sociohistórica, cultural, psicológica) de esta situación" (E.M. lopiansky \& all, $1990: 24$ ).

18 Nos limitamos a las estrategias que Camilleri identificó como las estrategias para restablecer el valor positivo de sí y no abordamos las estrategias para restablecer la unidad de sentido. El lector podrá consultar Cameliri (1990). 
reacciones identitarias individuales observadas en los primeros tiempos de la aculturación ${ }^{19}$ de los inmigrantes argentinos y ecuatorianos.

\section{LAS IDENTIDADES DEPENDIENTES}

Camilleri identifica una serie de estrategias identitarias que suponen una fuerte dependencia con las identidades atribuidas por el grupo mayoritario.

\subsection{Identidad negativa}

En el caso de la identidad negativa, el individuo interioriza el valor negativo atribuido a su identidad y adopta una actitud sumisa y recogida. Las entrevistas realizadas indican que esta actitud es más frecuente entre los ecuatorianos. La relación desigual que se establece entre españoles y ecuatorianos legitimiza implícitamente las identidades negativas y, en particular, la imagen del inmigrante miserable, víctima y sumiso, dispuesto a aceptar cualquier trabajo, condiciones laborales y salario.

Sin embargo, esta legitimización puede ser el resultado de una estrategia de identificación voluntaria, porque la relación desigual puede permitir al inmigrante ecuatoriano conseguir beneficios sociales, un empleo, que no lo echen, etc., por la pena y la compasión que inspira en la sociedad de recepción.

Los inmigrantes argentinos, en cambio, rechazan en su mayoría las identidades atribuidas negativas porque establecen relaciones sociales con los españoles a partir de una situación de igualdad fuertemente reivindicada. Esto, aún más, cuando, en el discurso, el inmigrante argentino compara su estatuto al de los inmigrantes españoles que fueron "muy bien" recibidos por Argentina y reivindica que se le dé el mismo trato en España. Por otra parte, el español tiende a considerarlo desde la igualdad porque socialmente no lo percibe como a los demás inmigrantes:

“(...) Yo me quedé en el albergue unos 2 ó 3 dias. La asistente social me consideraba como una española y decia que no podía estar en el estado en el que estaba. Porque soy blanquita y argentina me tocó eso. El tipo de albergue a donde iba era más bien para españoles marginados, alcohólicos, etc. Había una pareja de ecuatorianos que tenían que dormir con los alcohólicos en un sofá. Yo no, dormía en una habitación con baño. No viví todo lo que ellos vivieron. (...) Al principio, no me dieron trabajo porque cuando yo pedia cualquier tipo de trabajo, en Cáritas, Cruz Roja, me decian: "No, tú eres argentina. No te puedo dar este trabajo, es para los otros latinoamericanos". En realidad me di cuenta de que la gente que tiene rasgos aborigenes es para un tipo de trabajo". 20

19 Definimos la aculturación en los términos propuestos por Berry (2000:81): "La aculturacón se presenta como un proceso con distintas niveles. Originalmente, la noción designa el cambio cultural que resulta del contacto entre personas de diferentes culturas, a la vez dominantes y no dominantes (Redfield, Linton 1 Herskovits, 1936). Luego, se constató que los individuos implicados en iales situaciones de contacto sufrian lambién cambios psicológicos."

20 Verónica, 30 años, fue entrevistada en 2004. Es originaria de la provincia de Buenos Aires. Vive en Madrid desde 2002 y está trabajando cuidando a una persona discapacitada. En Argentina trabajaba como contadora en una empresa. 


\subsection{Identidades negativas desplazadas o asimilación}

La estrategia de asimilación le permite al inmigrante no interiorizar la estigmatización negativa. El inmigrante trata de asimilarse cultural y, en ciertos casos, físicamente a los españoles. A través de esta estrategia, el individuo se integra en el grupo de acogida, rechaza cualquier contacto con su colectivo de origen y termina desolidarizándose de él voluntariamente.

$\mathrm{El}$ análisis de los discursos de los inmigrantes entrevistados permite afirmar que esta estrategia es frecuente en los argentinos, en particular en aquellos que lograron una cierta estabilidad laboral dentro del ámbito de su especialidad. Generalmente, estos inmigrantes afirman haberse adaptado e integrado perfectamente y dicen identificarse con la forma de ser y de pensar de los españoles. Muchos se enorgullecen de hablar con acento y vocabulario casteIlano, reivindican un contacto exclusivo con los españoles y expresan una clara voluntad de vivir en barrios con baja concentración de inmigrantes con el fin de diferenciarse de ellos.

Para los inmigrantes argentinos que desarrollan esta estrategia de asimilación, la integración a la sociedad española supone a menudo la ruptura con su colectivo de origen instalado en España y, en ciertos casos, con la sociedad de origen. Muchos rehusan el discurso melancólico y rechazan categóricamente elementos identificadores de una memoria y de una identidad colectiva argentina, como pueden serlo el dulce de leche, la carne argentina, el mate y el tango. Construyen un discurso positivo sobre la sociedad receptora que contrasta con la mirada muy crítica que tienen acerca de sus compatriotas y de su sociedad de origen. Retoman los estereotipos negativos que circulan sobre los argentinos en España, los confirman e intentan diferenciarse.

"Desde que estoy aqui, no abri en Internet ni una sola vez Clarín u otro periódico. Corté completamente con Argentina. Yo no me relaciono con argentinos, no estoy dentro del ghetto argentino por decisión propia porque en el fondo no me gusta la idiosincrasia argentina. A mi me dicen siempre un piropo, que yo no parezco argentina. No sé como tomarlo. En todo caso el argentino es una persona que es soberbia, que quiere pisar cabezas, que tiene razón en todo y que sabe todo de todo. Yo ya me había dado cuenta de estos elementos de la personalidad de los argentinos pero en España se potencia. Yo adopté los modales y la forma de hablar de los españoles porque para mi es un elemento integrador y una exigencia de mi trabajo. Pero cuando me enojo hablo en argentino, cuando hablo de amor, hablo en argentino y pienso en argentino (...) En España, encontré los olores de la infancia, la alegría de la gente por la calle, cuando yo era chico, la gente silbaba por las calles en Buenos Aires. Los viejos tenian una sonrisa como los jubilados de acá, etc. Yo la verdad que me siento muy bien en España. Los españoles son muy cerrados al principio pero entendi que cuando te abren la puerta, te la abren de verdad. Yo tengo muy buenos amigos españoles, son muy solidarios. Yo sé que esta situación no es común. A mucha gente le ha sido imposible relacionarse con españoles. Quizás yo lo haya conseguido porque trabajo mucho para relacionarme con españoles, voy con mucho respeto pidiendo permiso y despacito. (...) 
Hay mucha gente que no soporta la experiencia en España. Yo conozco a mucha gente que se regresó. Creían que era más fácil. Se volvieron porque extrañaban todo: la carne, la comida, el dulce de leche... somos un tango caminando... Hay que ser muy fuerte para ser inmigrante. Si no tenés los objetivos claros y si estás con la melancolía la pasas fatal (....)".21

La estrategia de asimilación es menos frecuentemente en el caso de los inmigrantes ecuatorianos. En realidad aparece casi exclusivamente en los discursos de inmigrantes cuyo perfil socio-profesional y proyecto migratorio, exclusivamente individual, se parece al de los argentinos. Estos inmigrantes representan una minoría dentro del colectivo ecuatoriano ${ }^{22}$. Son, por lo general, jóvenes solteros de origen urbano de clase media con medios económicos, con formación profesional o universitaria que se definen a partir de la categoría "blancos-mestizos". Descartan así toda identificación con la categoría étnica y cultural del "indio" a partir de la cual la sociedad española define el colectivo ecuatoriano. El blancor de la piel se convierte entonces en un argumento estratégico de valoración identitaria porque el inmigrante entendió que la categorización por el color de la piel es sinónima de categorización social y cultural. Como el inmigrante argentino que desarrolla la estrategia de asimilación, el ecuatoriano se desolidariza de su colectivo de origen y reivindica en su discurso una sociabilidad con los españoles, como lo muestran las palabras de una joven ecuatoriana:

"Yo tengo siete años [en España], y yo, por ejemplo, con Daysi G., que tiene más o menos mi edad, hemos estudiado juntas, yo voy a su casa, ella va a la mía, ella tiene un coche, salimos a pasear, ella tiene su cumpleaños, yo el cumpleaños de mi marido, el mio y nos reunimos, y yo más tengo roce social con gente española, que con mis mismos paisanos, pero es por este problema, no porque no me gusta, o porque recién llegan, o por eso, no, yo los trato de evitar o sea por los comentarios que se hacen, o sea, se preocupan mucho de la vida ajena, ya, en ese sentido, a eso me quiero referir". ${ }^{23}$

La asimilación supone una aceptación por parte de la sociedad de acogida, ya que no puede asimilarse quien es rechazado. El grupo nacional tiene que aceptar al otro e identificarlo implícita o explícitamente como "capaz" de formar parte de su grupo. Al ser el colectivo ecuatoriano mucho más estigmatizado, sobre todo étnicamente, la sociedad española no le deja el mismo espacio que a los argentinos para asimilarse. Sólo el grupo "blanco-mestizo" con un nivel cultural similar al suyo puede conseguirlo.

21 Leo, 33 años, es originario de Buenos Aires capital y fue entrevistado en 2003. En Argentina, trabajaba como actor en el sector publicitario. En España sigue ejerciendo su profesión.

22 Fresneda (2003) considera que en España estos inmigrantes ecuatorianos no superaban el $20 \%$ del colectivo ecuatoriano en 2000. Pensamos que, desde entonces, esta cifra no ha aumentado de forma significativa. Utilizamos su categoría para definirlos.

23 Se trata del testimonio de Adriana, oriunda de Loja, Ecuador (Fresneda, 2003: 109). 


\section{IDENTIDAD POR DISTINCIÓN}

Según Camilleri, esta identidad ya no forma parte de las identidades dependientes y viene a ser lo que Malewska-Peyre (1990) considera una estrategia intermedia en la cual el individuo toma consciencia de su singularidad pero no interioriza las identidades atribuidas negativas. Establece una cierta toma de distancia con las identidades atribuidas, aceptando su diferencia. Estos tipos de discursos traducen una situación de equilibrio identitario que el individuo logra establecer. Esto da lugar a la elaboración de un discurso moderado y relativamente neutro sobre la sociedad de origen y la sociedad receptora como lo ejemplifican las palabras de Mariano, argentino de 28 años $^{24}$ :

"Ningún país es mejor que otro. Hay cosas buenas y cosas malas. Si hubiera un lugar perfecto estariamos todos viviendo en el mismo lugar y estarian todos contentos. Pero no es asi. Que uno esté aqui o allá no deja de ser un ser incompleto: antes quizás estabas rodeado de tus seres queridos pero no tenías ni un peso para tomar un café. Ahora tenés plata pero estás lejos de tus familiares".

El inmigrante establece una identificación con la sociedad receptora a partir de categorías amplias, como la edad, las ideologías, las creencias, el estatuto social, etc. (Malewska-Peyre (1990)). Antes de ser un inmigrante o un español, el individuo se autodefine como un joven, una mujer, un estudiante, un trabajador o en el caso de los argentinos, un "cuidadano del mundo". Al autodefinirse a partir de esta identidad universal, que aparece a menudo en los discursos de los entrevistados, los argentinos tratan de borrar las diferencias con los españoles.

Nos parece que esta estrategia es posible siempre y cuando las asignaciones identitarias sean relativamente débiles y no comprometan el equilibrio identitario del inmigrante. Por lo tanto, pensamos que los argentinos desarrollan con más frecuencia esta estrategia. Sin embargo, los datos recogidos durante los trabajos de campo nos permiten afirmar que esta estrategia es igualmente adoptada por un sector específico de la población ecuatoriana: las mujeres en búsqueda de autoafirmación. La sociedad ecuatoriana ejerce un control social muy importante de la mujer fuera del ámbito doméstico y limita considerablemente su libertad (Fresneda, 2003). Al ser muy fuerte la presión social, varios comportamientos, como el divorcio o el embarazo de solteras, son fuertemente sancionados. Frente a esta realidad social, algunas jóvenes solteras, madres solteras, mujeres divorciadas o con deseos de separación deciden emigrar en búsqueda de reconocimiento social. Estas mujeres, por lo general, parten de Ecuador con una imagen de sí desvalorizada y su salida tiene como meta permitirles recuperar su dignidad y afirmarse como protagonista de su propia historia. Esta inspiración es a menudo alcanzada con la emigración porque en gran medida está condicionada con un alejamiento del entorno familia y social de origen. Las asignaciones identitarias que estas mujeres tienen que encarar en España no afectan fuertemente sus identidades porque la emigración les

24 Mariano es oriundo de la provincia de Buenos Aires y fue entrevistado en 2003. Llevaba dos años viviendo en Madrid. En Argentina trabajaba como informático y había montado un cíber en Madrid. 
proporcionó un beneficio mayor y consiguen construir una identidad por distinción a través de la figura universal de la mujer digna y con derechos.

\section{IDENTIDADES REACCIONARIAS}

Camilleri (1990) identifica tres tipos de identidad reaccionaria: la identidad defensa, la identidad polémica y la identidad de principio o voluntarista.

\subsection{Identidad defensa}

Los inmigrantes ecuatorianos, en particular aquellos con poco nivel de estudio, en situaciones laborales y económicas precarias, parecen adoptar esta estrategia de defensa más a menudo que los argentinos. Como lo señalamos anteriormente, los inmigrantes ecuatorianos sufren de una mayor desvalorización de su imagen, lo cual sin duda condiciona reacciones identitarias más violentas y categóricas.

El inmigrante que adopta la identidad-defensa construye un discurso negativo del contexto social del país receptor y afirma claramente haber sido víctima de discriminación y exclusión. Esta exclusión termina presentándose a menudo en el discurso como consecuencia de un acto voluntario para atenuar sin duda su alcance. El inmigrante ya no se asume como víctima, como es el caso de los que adoptan la identidad negativa, sino como sujeto activo de su trayectoria migratoria, como lo ilustran las palabras de Lionel $^{25}$, inmigrante ecuatoriano:

"Aqui no me adapto todavía, y yo creo que tampoco pretendo adaptarme. En ese sentido soy un poco cerrado. Lo que me cuesta es la gente. No te deja integrarte. Los españoles son muy abiertos, conversan contigo, dialogan, todo lo que pueda ser, pero de ahi a que tú entres en el circulo de ellos, es imposible. Es imposible relacionarse con el grupo de ellos, o sea con amigos; no te dan ese espacio como para que te sientas cómodo. Eso me cuesta. Lo veo y prefiero estar a un lado, y no tener ese problema. En una conversación, tú no puedes casi opinar. O puedes hacerlo pero no cuenta tu opinión. El otro día estaba conversando con unos españoles y decian "todos los inmigrantes son malos". Entonces les contesté: "miren, yo soy inmigrante". Ellos me dijeron: "pero no estamos hablando de ti, de los latinoamericanos". "No-les digo-pero están diciendo "todos los inmigrantes" y, lastimosamente, yo soy inmigrante, de donde venga, soy inmigrante". "No-me dicen-pero nosotros estamos hablando de los marroquies". Siempre generalizan, si es uno, son todos, seamos buenos, seamos malos. De todo tiene que haber. Me dicen "no, pero no va contigo, va para los marroquies". "Da igual, nos estás nombrando a todos -le contesté-".

Este discurso negativo sobre la sociedad de recepción se opone a la elaboración de una imagen extremadamente positiva, en muchos casos idealizada,

25 Lionel, 28 años, es oriundo de Guayaquil, Ecuador, en donde trabajaba de protesista dental. Cuando to entrevistamos en 2003, estaba viviendo en España desde hacía dos años y no conseguia empleo por no tener papeles. 
de su grupo de origen. El país de origen y su gente son definidos por el inmigrante como más cálidos y acogedores en relación a la sociedad española, caracterizada por su extrema frialdad y distanciamiento. La reivindicación de su diferencia puede llegar a su máxima expresión en la configuración de la identidad-polémica en la que el individuo adopta una posición sumamente agresiva hacia el grupo mayoritario.

En el caso de la identidad-defensa, los inmigrantes ecuatorianos privilegian el contacto con sus compatriotas en España, refuerzan los lazos con Ecuador y algunos elementos simbólicos cobran para ellos un valor de emblema identitario (la comida, la música, etc.). El proyecto migratorio en España es presentado como provisional y, a menudo, si no se considera posible a corto plazo un regreso a Ecuador, se plantea imaginariamente la posibilidad de emigrar a otro país con gente "más cercana a su forma de ser". Así, la experiencia migratoria no se vive como un fracaso definitivo sino que se mantiene viva la posibilidad de éxito. En definitiva, la identidad defensa permite al inmigrante, por una parte, mantener de cierta forma la continuidad de su ser, ya que sus referentes identitarios siguen siendo los de siempre y, por otra parte, restablecer una imagen positiva de sí mismo.

Esta estrategia identitaria de defensa no está del todo ausente del discurso de los inmigrantes argentinos. Se observa en los argentinos cuyo discurso está saturado de expresiones y experiencias que revelan fracasos y denotan una gran frustración. Esta frustración está en la mayoría de los casos ligada a la ausencia de reconocimiento socio-profesional. La mayoría de los argentinos que emigraron a España pertenecen a la clase media, tienen un nivel de estudio alto y emigran con la esperanza de poder ejercer su profesión (García, 2005). Sin embargo, al ser difícil homologar títulos, incluso a veces el hecho de no tener papeles o entrar a competir con españoles, hace que pocos consigan trabajar en su ámbito laboral. Esta realidad, genera un gran resentimiento hacia la sociedad de recepción, resentimiento que comparten con los ecuatorianos que se auto-definen como "blancos" o "blancos-mestizos" de alto nivel profesional, quienes terminan trabajando en el servicio doméstico, la construcción o la agricultura. Empleos todos percibidos como desvalorizantes y, a menudo, humillantes (Fresneda, 2003).

Por otra parte, la frustración de los argentinos y de este grupo reducido de ecuatorianos surge del cuestionamiento fuerte de su identidad.

La identidad de los argentinos se construyó en gran medida a partir de la herencia socio,cultural de los padres y abuelos españoles o italianos que emigraron a Argentina a finales del siglo XIX y a lo largo del XX. Al llegar a España, estos nuevos inmigrantes argentinos desean impregnarse de la cultura peninsular y pretenden ser acogidos y tratados como nacionales ${ }^{26}$. Sin embargo, su integración y aceptación es cuestionada, en primer lugar, por las autoridades españolas, quienes no les otorgan sistemáticamente la doble nacionalidad y ni siquiera el permiso de residencia. En segundo lugar, algunos sectores de la so-

26 Este proceso se parece al observado y descrito por Galap (1986) acerca de la experiencia migratoria de los antilleses en Francia (citado por Malelewska-Peyre (2000)). 
ciedad española no reconocen la existencia de una supuesta "deuda histórica"27 con los argentinos y no los identifican como parientes, como lo testifican las palabras de un madrileño de 32 años:

"El país está malo, lo sé. ¿Por qué vienen a España? No creo que tengamos una deuda de gratitud por los emigrantes que acogieron en el siglo pasado. Era otra época. No han sido los casos de mis padres ni de mis abuelos". ${ }^{28}$ LA NACIÓN ON LINE, 18/06/01

Al descubrir esta realidad, el argentino vive una verdadera crisis identitaria, como lo testifican las palabras de $\mathrm{Nancy}^{29}$ :

"(...) Nosotros los argentinos siempre nos sentimos cercanos a los españoles, pensamos que somos hermanos por los lazos sanguíneos que nos unen. Entonces uno dice: ¿cómo es posible que ellos hayan venido a Argentina y que nadie les haya dicho nada y algunos realmente hayan hecho la América? ¿Por qué nosotros no somos aceptados de la misma forma? Para nosotros es como sentirnos excluidos de nuestra propia familia. Cuesta entender que es otra situación, otra época".

Sin embargo, es de notar que los discursos de los inmigrantes ecuatorianos no reivindican con tanto ardor, como los argentinos, lazos de filiación con los españoles. Quizás sea porque el marco histórico que movilizan es el de la época colonial con la figura de la "Madre Patria", pasado demasiado lejano para ser operante. Sin embargo, los inmigrantes ecuatorianos que se auto-definen como "blancos-mestizos" pretenden recibir un trato especial por parte de la sociedad receptora al llevar apellidos españoles y tener orígenes étnicos y socioculturales más cercanos a los españoles que muchos de sus compatriotas con rasgos étnicos mestizos e indígenas. Pero, como señala Fresneda (2003), este "clasicismo étnico" no tiene mucho eco y buena parte de la sociedad española no establece las diferencias étnicas que determinan las relaciones sociales en Ecuador. En consecuencia, este grupo de inmigrantes "sufrirá pues, el mayor choque de expectativas $y$, calladamente, el mayor cuestionamiento de su identidad y forma de relacionarse" (Fresneda, 2003:72). Al sentirse rechazado profesional y socialmente muchos adoptan una "identidad inmigrante o latinoamericana de resistencia" bastante agresiva (Fresneda, 2003). Los argentinos, en cambio, frente a la imposibilidad de realización de sus proyectos profesionales iniciales y al descenso de estatuto social que experimentan en España, desarrollan lo que llamamos las "identidades refugio". Afirman ya no identificarse con los españoles sino con los italianos como lo ejemplifican las palabras de Pablo: "Descubrí que finalmente nos parecemos más a los italianos y no tanto a los españoles. Yo no me quiero quedar en España sino que pienso irme cuanto antes a Italia". Otros tienden a reivindicar una identidad puramente

27 Muchos inmigrantes argentinos consideran que Argentina acogió muy favorablemente a los emigrantes españoles y evocan la ayuda alimenticia que su país proporcionó a España después de la Segunda Guerra Mundial. De esta forma, los inmigrantes argentinos afirman que los españoles tiene "una deuda" con ellos y deben ayudarles, ahora que lo necesitan, a integrarse.

28 Testimonio de un banquero madrileño de 35 años sacado de La Nación On line, "Cómo viven los argentinos", 18/06/01.

29 Nancy, 35 años, fue entrevistada en 2004. Llevaba dos años viviendo en Madrid y trabajando de camarcra. En Argentina trabajaba de contadora. 
argentina y no tanto latinoamericana. La idiosincrasia argentina rechaza toda identificación con los demás latinoamericanos y el inmigrante, al afirmar su "argentinidad", pretende mantener de cierta forma su especificidad.

La estrategia defensa es también operacional en la medida en que atenúa la "culpabilidad" que el inmigrante siente frente a los que se quedaron en el país de origen. El reivindicar fuertemente su identidad de origen permite atenuar a veces un cierto sentimiento de traición que resiente la sociedad de origen frente a sus emigrantes. Aunque no aparezca siempre explícitamente, los discursos de los inmigrantes entrevistados dejan vislumbrar en ciertos casos el conflicto que suscita la emigración en la sociedad de origen. La emigración en Ecuador es muy criticada. Los sectores más tradicionalistas la condenan por desestabilizar el orden tradicional de las relaciones sociales al permitir a ciertas mujeres ocupar un nuevo espacio dentro de la estructura familiar. Se convierten, en efecto, en jefes de familia, al mantener con el salario ganado en España a sus parientes instalados en España o en Ecuador. La Iglesia también en cierta medida condena la emigración por originar la destrucción del núcleo familiar. Muchos ecuatorianos emigran dejando a su pareja y a sus hijos a cargo de algún familiar. Por otra parte, la Izquierda y las organizaciones indigenas condenan a los emigrantes por no participar en la reconstrucción del país (Fresneda, 2003:59). Los sectores profesionales e intelectuales señalan las consecuencias a corto plazo para el país de la salida de la mano de obra joven.

En Argentina, después de la crisis, aparecen en la opinión pública dos representaciones contrarias sobre la emigración. La primera define muy claramente la emigración en términos positivos. El argentino que se queda en el país justifica y alienta la emigración de sus compatriotas por la ausencia de perspectivas económicas y profesionales en aquel momento. La otra representación, en cambio, ofrece una visión negativa de este fenómeno social. El argentino que se queda en el país condena y critica a los que emigraron porque defiende la idea según la cual, frente a la situación de crisis que atraviesa el país, la gente no tiene que huir sino "pelearla desde dentro". Este pensamiento se ve bastante bien reflejado en el éxito que tuvo en Argentina el reestreno de la obra teatral Made in Lanus ${ }^{30}$ de Nelly Fernández Tiscornia. En esta obra se elogia a los que se sacrifican por la reconstrucción del país y valoran el apego al terruño.

\subsection{Identidad de principio}

La identidad de principio consiste en una reivindicación fuerte de la pertenencia al grupo de origen cuando, en la práctica, se rechazan los valores y formas de ser del grupo. El corpus de nuestras entrevistas no nos permite afirmar con certeza si esta identidad es a menudo adoptada por los inmigrantes argentinos y ecuatorianos. Sólo hemos conocido el caso de una argentina que podría corresponder a esta estrategia identitaria. En su discurso, esta inmigrante se identifica exclusivamente con su grupo de origen, despreciando y criticando a la sociedad española. Declara no necesitar y, sobre todo, no querer estar en contacto con españoles. Su madre, que entrevistamos en Argentina, nos confesó que su hija se había vuelto "más argentina que nunca". Sin embargo, el

30 Fernández Tisconia, N. (2002), Made in Lanús, Ediciones Teatro Vivo, Buenos Aires. 
discurso de la inmigrante argentina deja vislumbrar una fuerte contradicción: afirma no tener ningún deseo de regresar a Argentina, ni siquiera para ir de visita y sostiene que, aunque la situación de Argentina se mejorara, ella nunca más viviría en su país de origen porque, en el fondo, "hay muchas cosas que no soporto de nuestra forma de ser y de actuar...".

\section{ALGUNAS ACOTACIONES FINALES}

Hoy en día, la sociedad española se enfrenta a un reto: construirse como sociedad pluricultural. La presencia significativa de la población inmigrante en España, la que desde los años ochenta no ha dejado de crecer, supone un contacto nuevo con la alteridad. Esta nueva relación con el "Otro" es a menudo conflictiva y supone una construcción negativa de la figura simbólica del inmigrante. La sociedad española le atribuye identidades fuertemente estereotipadas y desvalorizantes. Sin embargo, como hemos mostrado en este trabajo, la percepción que los españoles tienen de los inmigrantes varía en función de los colectivos. Algunos están más discriminados que otros y, en función del grado de aceptación, los inmigrantes desarrollan estrategias identitarias diferentes.

Los argentinos que reciben una mejor acogida que los ecuatorianos definidos esencialmente a partir de la categoría étnica, tienen un margen mayor en su elección identitaria. Al ser menos discriminados que los ecuatorianos, pueden interactuar socialmente con los españoles y ser entonces definidos a partir del aspecto personalizante. No están encerrados en categorías tan determinadas y les es posible adoptar estrategias más variadas y, sobre todo, más eficientes para su integración. Los inmigrantes argentinos tienden a adoptar mayoritariamente la estrategia de asimilación, la identidad por distinción o, en alguno casos más extremos, la identidad defensa. Las dos primeras estrategias identitarias privilegian claramente relaciones igualitarias y de cierta armonía con la sociedad española, lo cual favorece indiscutiblemente la integración de este colectivo. En cambio, los ecuatorianos adoptan con mayor frecuencia la identidad defensa y la identidad negativa que supone la construcción de relaciones conflictivas y desiguales con los españoles.

Por otra parte, al considerarse la identidad un proceso dinámico que se construye a partir de la interacción social (Goffman, 1975), podemos suponer que la identidad atribuida a los argentinos por la sociedad de acogida y, por lo tanto, sus estrategias identitarias, tienen más posibilidades de evolucionar y modificarse que las de los ecuatorianos por ser mucho más limitada su interacción con la sociedad española.

\section{BIBLIOGRAFÍA}

BERRY, J.W., (2000), "Aculturation et identité" in Costa-Lascoux, J., Hily, M.A., Vermès, G., Pluralité des cultures et dynamiques identitaires. Hommage à Carmel Camilleri, l'Harmattan.

BLANCO, C., (2000), Las migraciones contemporáneas, Ciencias Sociales, Alianza Editorial, Madrid.

CALVO BUEZAS, T. (2000), Inmigración y racismo. Asi sienten los jóvenes del siglo XXI, Cauce Editorial, Madrid. 
FRESNEDA, J., (2003), “Ecuatorianos en España. La construcción comunitaria de relatos saludables", Tesis defendida en 2003, Universidad Pontificia Comillas, Madrid.

GALAP, J., (1986), "Ethnicité et société: l'exemple antillais", Paris, colloque de l'Association Française d'anthropologie (multigraphié).

GARCIA, P., (2004), "La migración de argentinos y ecuatorianos a España: representaciones sociales que condicionaron la migración“, in M.R., Cozzani, Migrations en Argentine II, Cahiers Alhim ${ }^{\circ} 9$, Université Paris 8.

GOFFMAN, E., (1975), Stigmate, Éditions de Minuit, Paris.

GIL ARAÚJO, S., (2004), Documento de trabajo: “Inmigración latinoamericana en España. Estado de la cuestión", Instituto Universitario de Estudios Norteamericanos-Universidad de Alacalá \& International Florida University.

IZQUIERDO, A., LÓPEZ LERA, D., MARTÍNEZ BUJAN, R. (2002), "Los preferidos del siglo XXI: la inmigración latinoamericana" in GARCÍA, F., LOPEZ, M., La inmigración en España: contextos y alternativas, Vol II, Granada.

LIPIANSKY, E.M., TABOADA-LEONIETTI, I., VÁSQUEZ, A., (1990), "Introducción à la problématique de l'identité" in CAMILLERI,C., KASTERSZTEIN, J., LIPIANSKY, E., MALEWSKA-PEYRE, H., TABOADA-LEONETTI, I., VÁSQUEZ, A., Stratégies identitaires, PUF, Paris.

MALEWSKA-PEYRE, H., (1990), "Le processus de dévalorisation de l'identité et les stratégies identitaires" in CAMILLERI,C., KASTERSZTEIN, J., LIPIANSKY, E., MALEWSKA-PEYRE, H., TABOADA-LEONETTI, I., VÁSQUEZ, A., Stratégies identitaires, PUF, Paris.

MALEWSKA-PEYRE, H., (2000), "Dynamique de l'identité. Stratégies identitaires", in COSTALASCOUX, J., HILY, M.A., VERMÈS, G., Pluralité des cultures et dynamiques identitaires. Hommage à Carmel Camilleri, l'Harmattan.

MOLINER, P. (1996): Images et représentations sociales. De la théorie des représentations à l'étude des images sociales, Presses universitaires de Grenoble.

MORENO LORITE, C., VIDAL RODRÍGUEZ, J.A., (2000), Dos proyectos de intervención social con inmigrantes en el distrito de Moncloa, Junta de Distrito Moncloa, Servivios Sociales, Madrid.

RETIS, J., (2004a), "Tendencias en la representación de los inmigrantes latinoamericanos en la prensa nacional española. Colombianos, ecuatorianos y argentinos:jiguales o diferentes?" in Diálogo Comunicación y diversidad cultural. Forum Barcelona 2004. Ponencia.

RETIS, J., (2004b), “¿Miradas compasivas o atemorizadas? La construcción de las imágenes de los inmigrantes ecuatorianos y colombianos en la prensa española" in Construcción social de la inmigración: discursos y comunicación. $4^{\circ}$ Congreso sobre inmigración en España, Girona.

SANTAMARIA, E., (2002), La incógnita del extraño. Una aproximación a la significación sociológica de la "inmigración no comunitaria", Autores, textos y temas Ciencias Sociales, Anthropos Editorial, Barcelona. 